\title{
Tracking Future Graphics Education through Virtual Dystopian Spaces
}

\author{
Matteo Cavagliá \\ Luigi Cocchiarella \\ Veronica Fazzina \\ Simone Porro
}

\section{Abstract}

This paper aims at envisioning prospective fragments of future scenarios in the field of graphics education in architecture. The inspiration comes from the recent rapid evolution affecting the approach to digital representation in the Schools of Architecture. After a long «dormant» phase, the digital and the internet have shown a tremendous rise, not only on the academic channels but also in our everyday life. In addition, the appearance of Covid- 19 worldwide has made them necessary supports for and virtual surrogates of plenty of actions traditionally happening face to face. Consequently, for about a year now, technology has been at the core of the massive communication strategies activated to mitigate the effects of social distancing. Showing in addition an interesting contrast: while on the one hand the real world seems to have been widely flanked by, or, sublimated into dystopic «virtual bubbles», on the other hand, just that virtual bubbles seem to tend to acquire a status of «real places» in a large part of our lives. Which in our opinion deserves our disciplinary attention, since that new pretentious real places are made of the same matter of representations in fact. Here languages become relevant. Then our research question is: may the mentioned dystopian visionary worlds generated by the digital be also of help, apart from their instant fascination, in envisioning fragments of the future operational scenarios waiting for us in architectural graphics education?

Keywords

digital technologies, dystopia, graphics education, visual representation, distance learning.

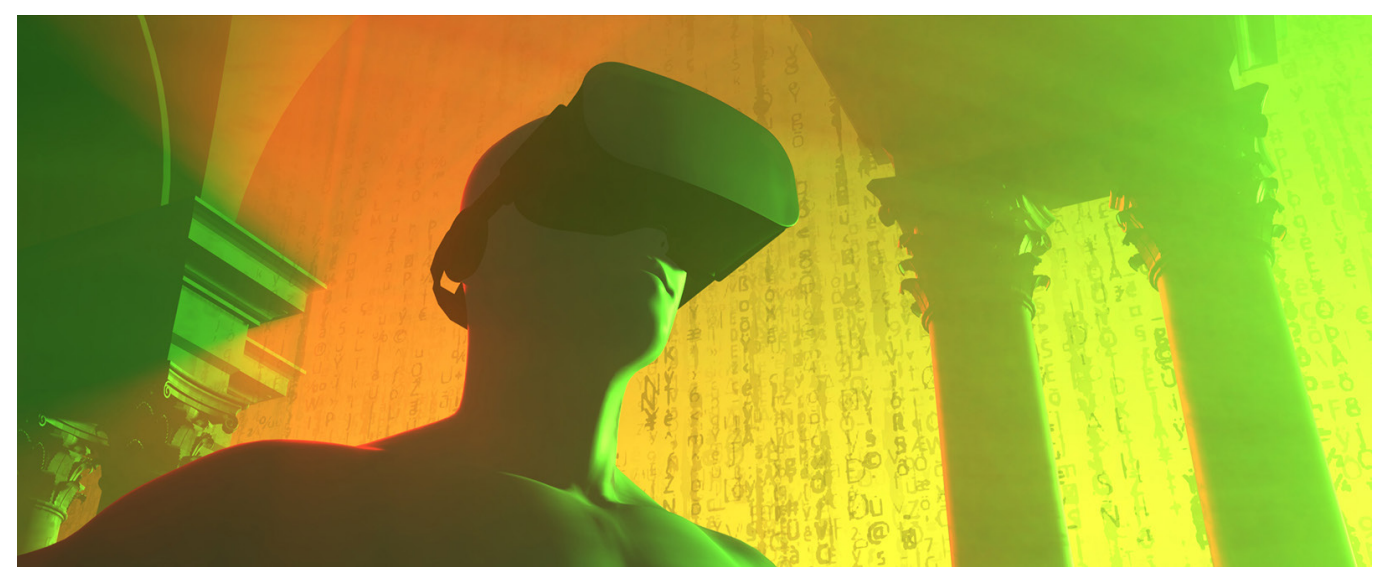




\section{Introduction - an epoch-making conjuncture}

The temporal context in which this article is written is emerging as a historical crossroad for the digital evolution, dictated by recent technological developments, some already accessible and others that might be soon available to the masses, as well as by Pandemic, that has led to a forced digital shift of activities and processes that until recently were still analog. The pandemic spread of COVID- 19 has drastically changed many aspects of our lives and inside this scenario, technology has day by day played one of the most relevant roles should ever be supposed, that of a cornerstone for strategies to overcome the distances that were taking us apart. In a sense, technology allowed society to keep functioning. In the field of University education, which is our specific field of interest, the pandemic has provided the disappearance of boundaries from physical classrooms and their expansion into dystopian «virtual bubbles» with no predefined dimensions, reachable by all the users, and also available for asynchronous uses. After evoking it for long years, suddenly with the lockdown we welcomed technology changes in education [Chiarotti 2020, pp. 36, 37]. We accepted distance learning and the consequent interaction with interfaces and new communication flows. Expelled the physical bodies from the scene, we only dealt with languages, and with a new levity of the educational contents. As a result, we had the feeling to have been transposed in another world, meeting new kinds of imageries. That's why we spontaneously looked at other contexts, like cinematography and video gaming, whose dystopian immateriality seemed to have a higher potential in predicting future scenarios, also thanks to their pure computer graphics constitution, compared to the tangible architectural contexts whose physicality imposes slower rates of utopian freedom and innovation (fig. I). Although the mentioned digital contexts are, of course, more evocative than really transposable into physical spaces, we think they may exert a push towards a more decisive integration of digitization in our own world, which is supposed to be a relevant topic to face, even in graphics education, and of course in Architecture.

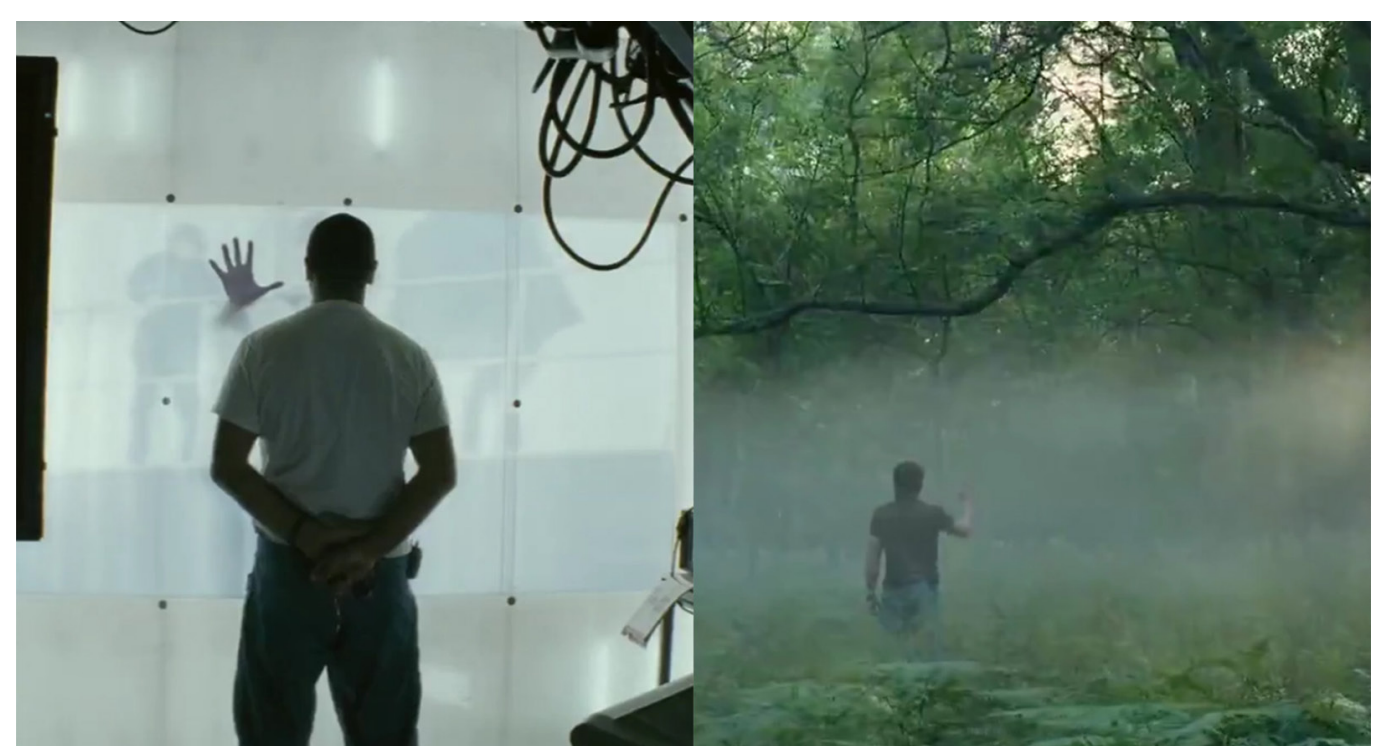

\section{Technology dystopia}

One of the clichés deriving from years of marketing, theories of capitalist evolutionism, and social and mass psychological conditioning, shows the ideas of progress and technological evolution associated with a positive connotation. Which is not necessarily true: the high technology of a tank is not necessarily synonymous with positivity, nor with social or cultural 
evolution, but only with a purely technical enhancement, while its use only determines its positivity or negativity. Some time ago Heidegger defined the early beginning of our epoch as an emerging «age of technique», where mankind dared to «provoke» nature to exploit natural resources and, at the same time, to discover the true essence of nature itself. Concluding that technique is not much about mere creation of objects, but more about understanding objects as part of a system revealing the «asset», which nature makes available, and which objects need to be consistent with. We see this as the beginning of a dystopian process where technique tries to replace nature. Over time physic systems have been further expanded by virtual addictions, and the technology developments led changes in the society that are much deeper than we believe or see on the face. The impact of the digital on the physical has been such that nowadays the former often balances the latter, so that we can talk with no surprise about digital reality. And the process is still on the way. Initially hybridly flanking physicality, the digital is now starting to try to fertilize even organic life. In our perspective, the latest dystopian transposition. We greeted early advances in Artificial Intelligence with enthusiasm and pride, despite several warnings about potential dangers of Al, many of them still to be addressed. For decades we have been terrified of the Frankenstein myth, but recent is the news of Elon Musk's experimentation of the introduction of electrodes inside the human brain (Neuralink), giving away that man-machine connection about which many, especially in science fiction books, have already written. And other examples may be adduced (fig. 2). All this, seems to even stress the primary Heidegger's conclusions, leading us to confront ourselves with spaces and objects that are no longer genuinely physical, but also/instead virtual, and with forms of intelligence that do not think with a genuine human logic, even though emulating it anyway, opening up to new technology transpositions, more or less proximate, that we might, again, call dystopian. All in all, the hard controversial discussions running on, and still expected on the topic, suggest us to keep paying new attention to the mentioned technology clichés, looking for warnings, and opportunities.

Fig. 2. Opponent dystopian transpositions: Matrix, Lana and Andy Wachowski, USA, 1999 (left); Korf 17 small, Emanuele Giannelli, 2017 (right)

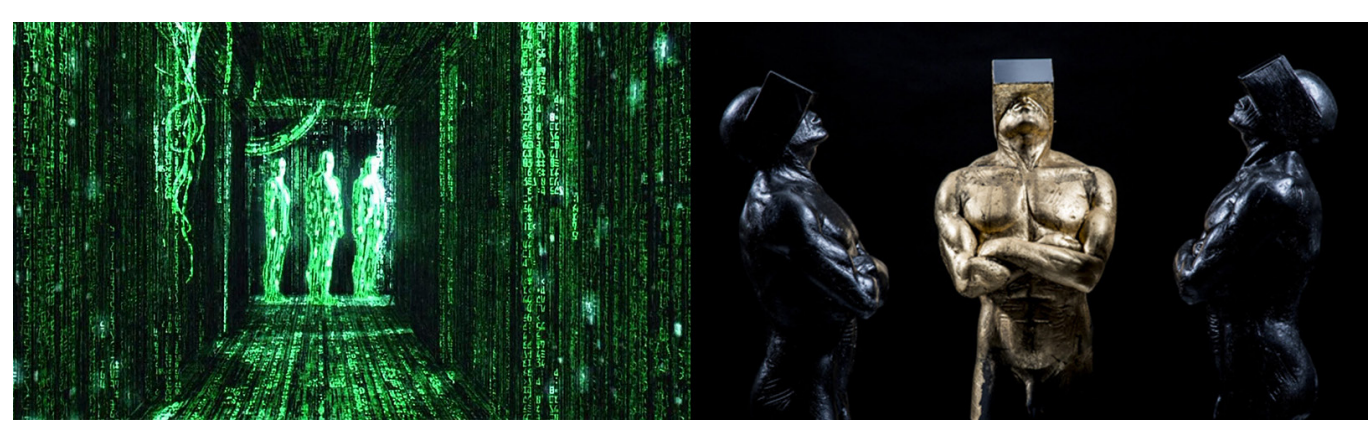

\section{Distance imperative}

Pandemic has made interpersonal distancing imperative. Which has also been prerequisite for the wide access to the dystopian worlds made available by digital technologies. One of the major changes for the society involved, seems to concern the redefinition of the spatial concept of place (physical topos), which is gradually losing its physicality to find a digital counterpart (digital topos) in enclosure circumscribed by computerized fences. Each enclosure can be isolated from the world around without any physical connection with it (digital-world, kind ofVR) or, be somehow connected with it (physical-digital world, kind of AR). In the latter case, taking the virtual classrooms as a reference, they can be regarded as hybrid extensions of real spaces, where the sense of distance among physical places is temporarily suspended, and replaced by the experience of being there and distant at the same time during live broadcastings. That is, dystopian environments where, 
differently from traditional Utopia, we can actively and socially act in real time. In this new type of learning spaces, one of the educational challenges may lay in managing interactions between physical and digital workflows. We may again evoke cinematographic imagery to consider the ongoing paradigm shift, like the extreme scene from the digital world Construct in the film Matrix (fig. 3). In that context the foundations on which scientists and researchers to date have based and defined theories and scientific foundations of all physics culture until now, necessarily cease to have any value, unless that digitally generated world is some more or less based on the perceptual emulation of our real world. Then, in the new hybrid interactive environment of the virtual classrooms, where each of the many dimensions and components at work can be isolated, unrolled, blocked and sent back or forth, like in a film, with several levels of possible real time interaction, we should even reconsider basic concepts like space, time and energy, in relation with the principles to which those who are behind the screen in the physical world are subjected. In other words, we have to deal in a new way with the interactions between reality and representations.

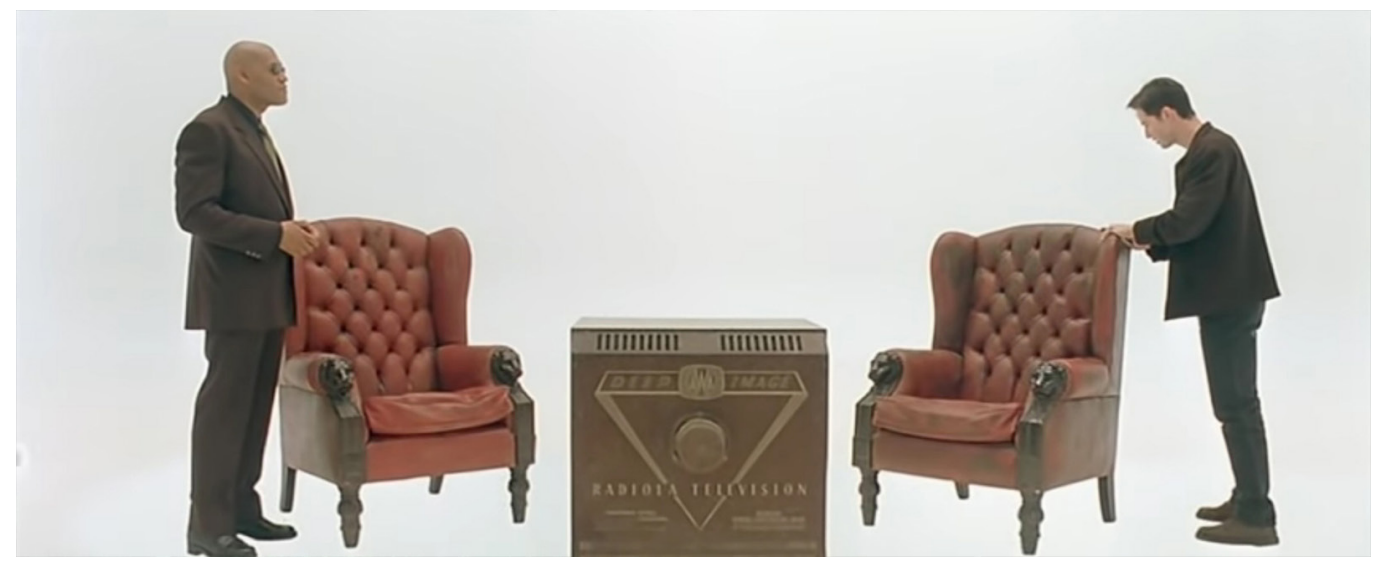

\section{Representation based reality}

As we already said, the digital transition to dystopian environment basically follows two ways. The conversion of the physicality of our world into digital information by input tools: mice, microphones, video cameras, scanners, etc. (physical-digital world, leading to AR). Or, the generation of a digital information world completely detached from the physical one (digital-world, leading to VR). Several levels of hybridization are possible between these two extremes, both based on the computer code, speaking for itself a non-dimensional language, but flexible enough to match any semantics. Acting essentially with the same logic with which a prosthesis links the mechanical component to the biological one, that would not be needed if one had the possibility to also interact more directly with the digital space. What has been shown in some movies like Avatar, Black Mirror, Interstellar, Inception (fig. 4) and the already mentioned Matrix, might be achieved, for instance, with Mind UploadingTechnologies, by copying, translating or in some way linking mental components to a non-biological substrate, or, by implanting electronic devices inside the biological substrate. Back to the purpose of this paper, we would only highlight the paradigm shift from the «material» to the «information» level in this virtualization process. Maybe our traditional idea of Graphic Representation as a set of knowledge and processes able to control the transition from 3D spaces to 2D images and vice versa, and then from 3D spaces to 3D or 3D+ models and vice versa, is to be reconsidered also in the light of the distance-learning experience we have been forced to carry out in the last year. From our disciplinary point of view, this 
experience has also highlighted a kind of «osmotic» relationships between physical reality and representation, since the latter provides either spatial contexts, either didactic materials for education, while hosting real humans manipulating their invisible wires behind the stage. In other words, dystopian contradictions seem like mitigated in this interactive representational environment.

Fig. 4. Information-based beyond Physicalitybased dystopian spatial suggestions: Interstellar. suggestions: Inters
USA, 2014 (left): Inception, USA, 2014 Inception,
(right).

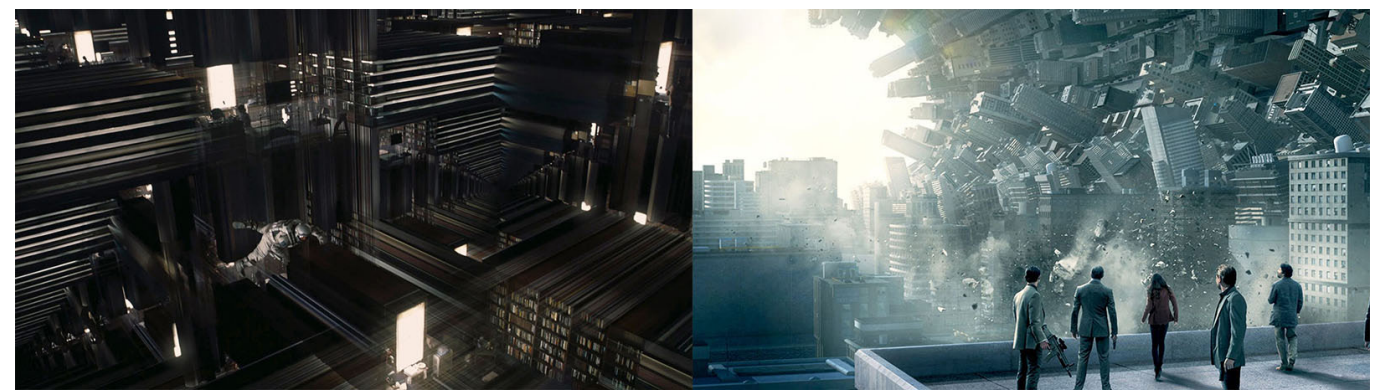

\section{Back to the teaching}

Indeed, the digital bridges provided by online classrooms offered themselves as a test-case which, albeit obviously different from a physical room, allowed the continuation of the learning experience during the Pandemic. In this sense we can talk of the dystopian places mentioned above as experienceable virtually augmented spaces, where everything becomes representation in order to disclose information. This trial was undoubtedly hard for many, but there are merits in pursuing a better understanding of all the parts involved. At a first glance, the approach to distance learning seems quite different from a face to face one, however, it also suggests us to consider the benefits of acting in a more homogeneous digital environment. On the purpose, we may remember the words of George Nelson about the first tests on mixing technological aids in education: "The voices, music, and sounds were electronically recorded, amplified, and played back. But it was people who said the words, wrote the music, and made the final statement. This is why there is no need to be afraid of our tools - even in education. The teacher may become less visible in the new classroom, but he will still be there" [Abercrombie 1995, pp. I45-149]. It may seem hard to believe that such words were spoken about events dating back to 1952. Similarly, the present propensity to increase the interactivity via electronic interfaces, as if moving in a video-gaming environment or inspired by cinematographic visions, may be considered as a new stage in the enhancement of the class experience, based on the support of innovative technologies, which need to be taught and learnt (fig. 5). A renovated and more advanced digital literacy is therefore required to pursue new challenging chances in education. Similarly to the fantastic world of Flatland by Edwin Abbott Abbott [Abbott Abbott 1966], and to its many dimensions and sensory opportunities [Chiarotti 2020, pp. 36, 37], we can consider the present digitally informed space as a new kind of Thougthland, a revolutionary space difficult to explain to and to be understood by those who do not belong to that reality. As educators, we have not to forget that, although digital-based didactic contexts tend to dematerialization, the communication conveyed by digital channels and devices has a real cognitive impact on the students, which makes their experience real, as well as the learning outcomes. Concerning contents, inside a distance-learning environment, more than in a traditional face to face educational context, the whole linguistic richness of the representational forms and codes is available, that is, including all the degrees of iconicity from visual to verbal descriptions, as Abraham André Moles [I] would say, giving place to endless series of combinations of realism, abstraction, and symbolism, so crucial to our disciplinary semantics. 
Now we need to ask ourselves about details concerning what the teaching of architectural graphics representation may hold in the future, how it may be re-configured, integrating in-place and distance education. Which means, we have to go back and review our strategies and syllabuses.

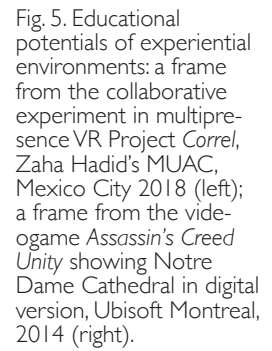
2014 (right).
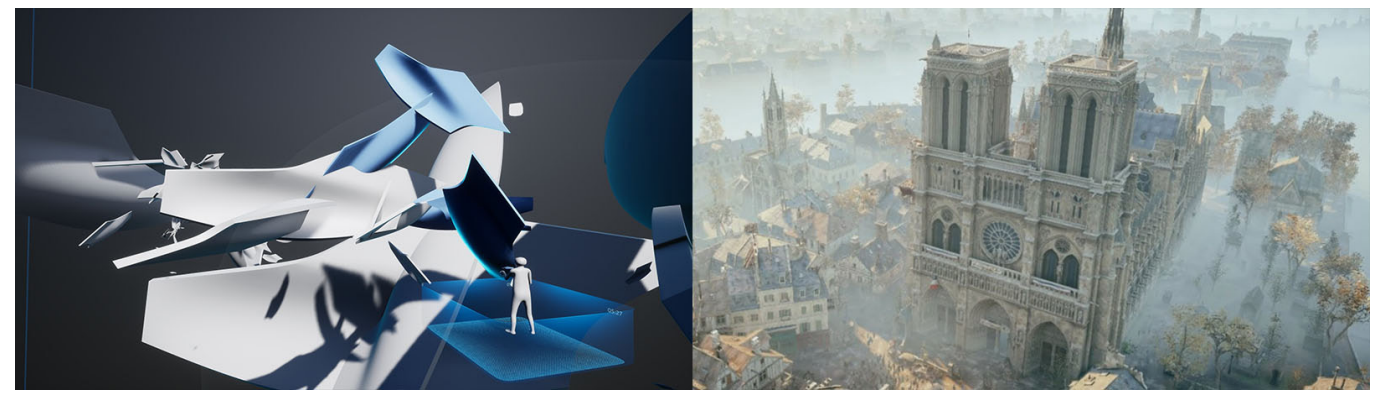

\section{Conclusions - open}

The challenges of our time revolve around new tools, and we are again witnessing the rise of a new generation. If digital natives were the ones that grew up alongside digital tools, we face now young communities definitely growing up in confidence with the virtual. Where will this lead us, it is impossible to predict, but it was somehow expected. In recent years the idea that one day, people would have considered virtual and augmented spaces just as normally as the physical ones, was already quite diffused [Rubin 2014, pp. 56-67]. A prelude to this was also offered by digital cinematography and videogame design, to which we also referred in this paper, somehow comparing their envisioning power to that of traditional utopian imagery. From this fascination architects have been already attracted, making great progresses in the last fifty years, as we can see comparing, for instance, Arata Isozaki's media installation Electric Labyrinth [Domusweb 2003], still based on projecting images and movies, with the interactive Lawrence Lek's project Shiva's Dreaming for Re.presence, a videogame where a multimedia 3D reconstruction of the Crystal Palace shows many sides of its story and design, including the fire [Disegnodaily 20I4] (fig. 6). And many other examples could be mentioned. But we hardly have similar applications in the official architectural educational programmes. To access these new scenarios, and the related imageries, new skills are needed, clear educational goals are to be focused, and detailed curricula are to be tailored to match specific disciplinary targets, beyond the urgency of an emergency. Moreover, as we already wrote, in a distance-learning context, both educational environment and contents conveyed are made of the same «matter» of representations, mostly graphic representations. Thiago Klafke, senior environment artist at Blizzard Entertainment, sharing some thoughts for ArchDaily said: "we are usually constructing fictitious worlds, we have total freedom [...] we can shift things around, design impossible buildings and materials, and composite the scenes in a way that doesn't necessarily make sense, but that conveys what we want to express" [Stouhi 2020]. In conclusion, as Mario Carpo would suggest, a new cross-disciplinary field is to be investigated in order to match the traditional world of "alphabet" with the one of "algorithm" [Carpo 20I I], which is supposed to become a more and more relevant part in the University agenda. Assuming specific knowledge will prevent educators and students from naïve enthusiastic engagements, as well as the future professionals, according to what some sensitive authors like Antoine Picon [Picon 20 I0] and others are already pointing out from some time. At the moment we are still in-between, but maybe we are looking in the right direction. Which seems to reflect our present state of mind, where a wish more than a clear picture can be outlined, and much is still to be learnt and done. 
Fig. 6. Comparing dystopian performances over time: Electric Labyrinth by Arata Isozaki, 1968 (left); Shiva's Dreaming, a videogame about the destruction of the Crysta Palace, by Lawrence Lek, 2014 (right)

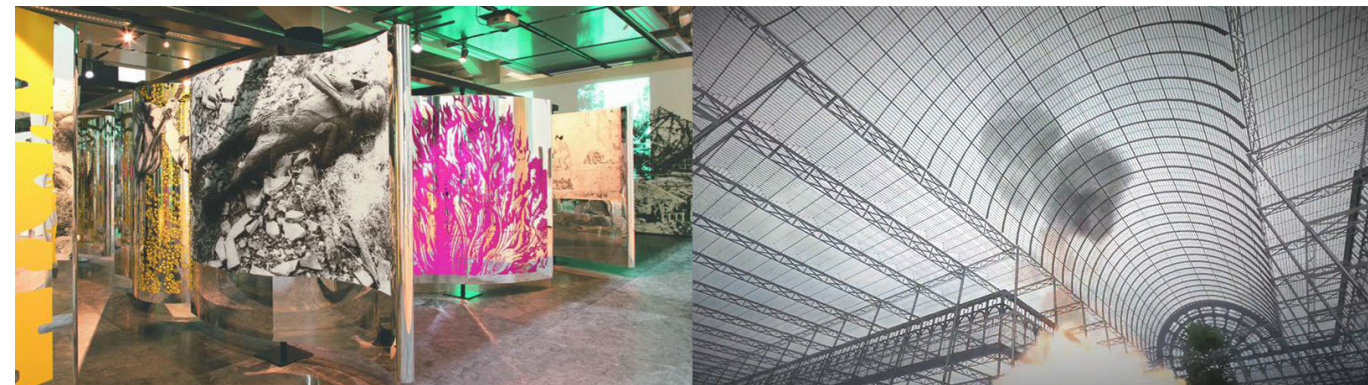

Note

[I] Moles is responsible for the conclusive document to a seminar in 1965 that contains a catalog of the levels of iconicity

\section{References}

Abbott Abbott E. (1966). Flatlandia. Racconto fantastico a più dimensioni. Milano: Adelphi.

Abercrombie S., Nelson G. (1995). The design of modern design. Cambridge: MIT Press.

Anceschi G. (1992). L'oggetto della raffigurazione. Milano: Etas Libri.

Baricco A. (20|8). The game.Torino: Einaudi.

Carpo M. (20I I). The Alphabet and the Algorithm. Cambridge (MA): MIT Press.

Falcinelli R. (20 I I). Guardare, pensare, progettare. Neuroscienze per il design. Roma: Stampa Alternativa \& Graffiti.

Hofstadter D.R. (1996). Concetti fluidi e analogie creative. Milano: Adelphi.

Maldonado T. (1992). Reale e Virtuale. Milano: Feltrinelli.

Picon A. (20 10). Digital Culture in Architecture. An Introduction for the Design Professions. Basel: Birkhäuser.

\section{Website}

Chiarotti C.Memoire <https://issuu.com/carolinachiariotti/docs/memoire_carolina_chiariotti_> (accessed 2020, February I8).

Gilbert B. The stunningly detailed re-creation of Notre-Dame Cathedral in an 'Assassin's Creed' game could help with the rebuilding efforts. Here's what it looks like up close, 2019 April, 17. <https://www.businessinsider.com/notre-dame-cathedral-interiorassassins-creed-unity-2019-4? IR=T> (accessed 2020, February |8).

Re.presence: How to See Architecture. In Disegnodaily. (2014 May, 22). <https://www.disegnodaily.com/article/re-presencehow-to-see-architecture> (accessed 2020, February 18).

Rubin P. (20|4). II ritorno della realtà virtuale. Quel mondo adesso è qui. La vera storia di Oculus Rift e di come il futuro non sia mai stato cosi presente. In WIRED, no. 63, June 2014

Ruins of the future, in Domusweb 2003 May, 26. <https://www.domusweb.it/en/art/2003/05/26/ruins-of-the-future.html> (accessed 2020, February 18)

Stouhi D. From Backdrop to Spotlight: The Significance of Architecture in Video Game Design (2020 June, 16). <https://www. archdaily.com/938307/from-backdrop-to-spotlight-the-significance-of-architecture-in-video-game-design> (accessed 2020 February |8).

<https://www.domusweb.it/en/art/2003/04/I7/isozaki-s-electric-labyrinth-in-turin.html> (accessed 2020, February 18).

<https://www.youtube.com/watch?v=aoak753r6-Q> (accessed 2020, February I8).

\section{Authors}

Matteo Cavagliá, Politecnico di Milano, cavaglia.matteo.main@gmail.com

Luigi Cocchiarella, Politecnico di Milano, luigi.cocchiarella@polimi.it

Veronica Fazzina, Politecnico di Milano, veronica.fazzina@polimi.it

Simone Porro, Politecnico di Milano, porrosimone@gmail.com

To cite this chapter. Cavagliá Matteo, Cocchiarella Luigi, Fazzina Veronica, Porro Simone (2021).Tracking future graphics education through virtual dystopian spaces. In Arena A., Arena M., Mediati D., Raffa P. (a cura di). Connettere. Un disegno per annodare e tessere. Linguaggi Distanze Tecnologie. Atti del $42^{\circ}$ Convegno Internazionale dei Docenti delle Discipline della Rappresentazione/Connecting. Drawing for weaving relationship. Languages Distances Technologies. Proceedings of the 42 $2^{\text {th }}$ International Conference of Representation Disciplines Teachers. Milano: FrancoAngeli, pp. 37I-377. 